\title{
Flow and Engineering Properties of Fiber Reinforced Hwangtoh Mortars
}

\author{
Mun, Ju-Hyun ${ }^{1 *} \quad$ Yang, Keun-Hyeok ${ }^{1}$ Hwang, Hye-Zoo ${ }^{2}$ \\ Department of Architectural Engineering, Kyonggi University, Yeongtong-Gu, Suwon, 443-760, Korea ${ }^{1}$ \\ Department of Architecture, Mokpo National University, Muan-Gun, Jeonnam, 534-729, Korea ${ }^{2}$
}

\section{Abstract}

In this study, six mortar mixes were tested in order to examine the significance and limitations of hydrophilic fiber in terms of its capacity to enhance the tensile resistance of Hwangtoh mortar. Lyocell, polyamide and polyvinyl alcohol (PVA) fibers were selected for the main test parameters. The tensile capacity of mortars tested was evaluated based on the splitting tensile strength and the modulus of fracture, while their ductility was examined using the toughness indices specified in ASTM. Test results showed that the addition of lyocell and PVA fibers had little influence on the flow of the Hwangtoh mortars. To enhance the tensile capacity and toughness index of Hwangtoh mortar, it is proposed that fiber spacing above 0.0003 is required, regardless of the type of fiber.

Keywords : hwangtoh mortar, fiber reinforcing, tensile capacity, engineering properties.

\section{Introduction}

While cement ranks alongside steel as one of most important materials in the construction industry, it emits about 0.81 tons of carbon dioxide $\left(\mathrm{CO}_{2}\right)$ in the manufacturing process[1]. Since the carbon dioxide emitted by cement represents about $7 \%$ of all carbon dioxide emissions, the demand to develop a technology to reduce the level of carbon dioxide has been increasing. For this reason, companies in the construction industry have a high interest in binders to replace cement, and attention is being given to such Kaolin-type materials as flyash and Hwangtoh[2-7].

Hwangtoh concrete has been studied, in which part or all of cement is replaced with Hwangtoh binder or Alkali-activated inorganic binder[4-7]. In

Received : March 9, 2012

Revision received : April 5, 2012

Accepted : April 12, 2012

* Corresponding author : Mun, Ju-Hyun

[Tel: 82-31-249-9702, E-mail: munjh@kgu.ac.kr]

(c)2012 The Korea Institute of Building Construction, All rights reserved. general, mortar or concrete with Hwangtoh binder is usually shown to have a lower tensile property than cement concrete[5-7], which serves as one of main the causes of deterioration in the usability and durability of a structure. Fiber addition can be considered as one of the methods to improve the tensile performance of Hwangtoh concrete. Hwangtoh binder, which has a higher absorption rate than cement, can lower the initial fluidity of concrete, which accelerates the fiber balling of the added fiber. Thus, hydrophilic fiber is more effective in improving the tensile performance of Hwangtoh concrete.

The effect of hydrophilic fibers such as lyocell, polyamide and polyvinyl alcohol (PVA) on the initial flow and mechanical characteristics of Hwangtoh mortar was studied. The mechanical characteristics include compressive strength according to age, stress-strain curve, coefficient of elasticity, splitting tensile strength, modulus of rupture and toughness index. Compressive strength according to age was compared to ACI 209 criteria[8], and the improved ductility obtained by fiber reinforcement 
was evaluated using the toughness index presented in ASTM C-1018[9].

\section{Experiment}

\subsection{Specification for mix proportion}

Six different Hwangtoh mortar mixes were prepared by adding different types and amounts of commercially available hydrophilic fiber. The Hwangtoh mortar specimens were divided into two groups. Table 1 indicates the specification for mix proportion. The primary variable in the first group is lyocell, which was added to be $0.049 \%$, 0.098\%, and $0.195 \%$ of the entire volume, respectively. The primary variable in the second group is the fiber type, including PVA and polyamide. Taking into account the optimal amount required for the mix proportion at a site, PVA and polyamide were added to be $0.070 \%$ and $0.043 \%$ of the entire volume, respectively. The water-binder ratio and fine aggregate-binder ratio were set to $40 \%$ and 2.5 of mix proportion, respectively, and polycarboxylate plasticizer was used to meet the target flow of $200 \pm 10 \mathrm{~mm}$.

\subsection{Material properties}

The calcined Hwangtoh used as a binder was activated by alkali metal ion, the specific gravity and fineness of which were 2.8 and $3200 \mathrm{~cm}^{2} / \mathrm{g}$, respectively. Table 2 shows the physical and mechanical characteristics used in this study. The length of all the fibers used in this research was $13 \mathrm{~mm}$ or less, meaning they could be classified as micro fibers, and aspect ratio ranged from 262 to 727. In particular, the PVA fiber was about twice as large in aspect ratio compared to other fibers, and its tensile strength is also 1.5 times higher.

Natural sand used as fine aggregate had a maximum radius of $4 \mathrm{~mm}$ and a specific gravity of 2.42. The natural sand met the requirements of the KS Particle Size Distribution Curve, and its fineness modulus was 2.51 .

\subsection{Mixing method and testing}

Hwangtoh mortar was mixed by a forced mixer alternating dry and wet mixing for periods of 1 minute and 30 seconds. To meet the target flow, the amount of plasticizer was adjusted and mixed. The steel molds were eliminated from all specimens after 1 day of age, and the specimens were cured at $21 \pm 2^{\circ} \mathrm{C}$ and $60 \pm 5 \%$ of relative humidity in a constant temperature and humidity room. The fresh mortar was placed in a test mold in three $2.5 \mathrm{~cm}$-thick layers and dropped from a height of $1.27 \mathrm{~cm} 25$ times to measure the flow immediately after mixing[10]. After hardening, the compressive

Table 1. Mix proportion of hwangtoh Mortar

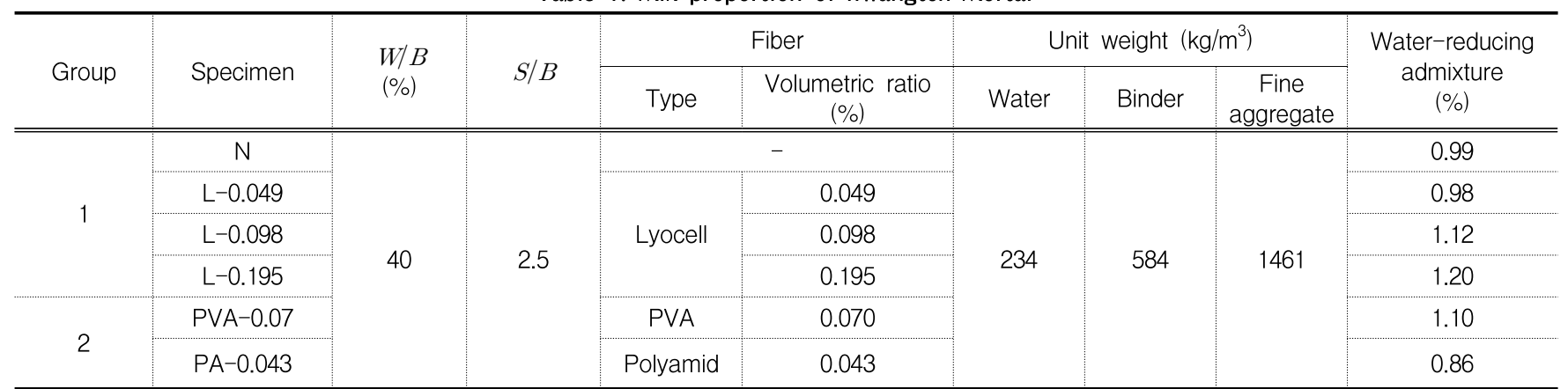

$W / B$ and $S / B$ are water to binder ratio and fine aggregate to binder ratio, respectively.

In specimen notation except a control mortar $\mathrm{N}$, the first letter indicates the type of fiber added and the second part refers to the volumetric ratio of the fiber. in addition, L, PVA and PA refer to Lyocell, Polyvinl alcohol and Polyamid fibers, respectively. 
Table 2. Physical and mechanical properties of fiber used

\begin{tabular}{ccccccc}
\hline Type & $\begin{array}{c}\rho_{f} \\
\left(\mathrm{~g} / \mathrm{cm}^{3}\right)\end{array}$ & $\begin{array}{c}d_{f} \\
(\mathrm{~mm})\end{array}$ & $\begin{array}{c}L_{f} \\
(\mathrm{~mm})\end{array}$ & $S_{f}$ & $\begin{array}{c}T_{f} \\
(\mathrm{MPa})\end{array}$ & $\begin{array}{c}E_{f} \\
(\mathrm{MPa})\end{array}$ \\
\hline \hline Lyocell & 1.23 & 0.040 & 13 & 325 & 850 & 31300 \\
PVA & 1.3 & 0.011 & 8 & 727 & 1269 & 27640 \\
Polyamid & 1.4 & 0.023 & 6 & 261 & 594 & 3900 \\
\hline
\end{tabular}

$\rho_{f}=$ density, $d_{f}=$ diameter, $L_{f}=$ length, $S_{f}=$ aspect ratio, $T_{f}=$ tensile strength, $E_{f}=$ modulus of elasticity

strength was measured in $\varnothing 100 \times 200 \mathrm{~mm}$ mold at 1, 3, 7, 28, 56 and 91 days. In addition, stress-strain curve, the modulus of elasticity, splitting tensile strength, modulus of rupture, and flexural load-deflection curve were measured at 28 days. The stress-'strain curve and the splitting tensile strength were measured in the $\varnothing 100 \times 200 \mathrm{~mm}$ mold, and the modulus of elasticity was calculated using the slope of the tangent line at $45 \%$ of the maximum stress from the stress-strain curve[11]. The modulus of rupture and the load-deflection curve were measured in the one-point concentrated load bending test for the $150 \times 150 \times 550 \mathrm{~mm}^{-}$-sized mold. The toughness index was calculated in the ratio of the respective area measured between the starting point and $3 \delta_{c}, 5.5 \delta_{c}$, and $10.5 \delta_{c}$, and the area measured between the starting point and the first cracking deflection $\left(\delta_{c}\right)[9]$.

\section{Test results and analysis}

\subsection{Flow}

The fluidity of the Hwangtoh mortar specimens was assessed for each mix rate of plasticizer. The mixing rate of $\mathrm{N}$ specimen, to which no fiber was added, was shown to be $0.99 \%$ of total binder. As indicated in Table 1, the mixing rate of plasticizer in fiber reinforced Hwangtoh mortar was shown to be $0.98 \%$ at the optimal mixing amount, which was similar to that of $\mathrm{N}$ specimen, but the mixing rate of plasticizer was increased in the range higher than the optimal mixing amount. In particular, when twice as much lyocell was added, the mixing rate of plasticizer was 1.1 times higher. The mixing ratio of plasticizer in polyamide reinforced Hwangtoh mortar was shown to be $0.86 \%$, which was lower than that of $\mathrm{N}$ specimen. On the other hand, the mixing rate of plasticizer in PVA reinforced Hwangtoh mortar was shown to be higher than that in lyocell or polyamide reinforced mortar. It is believed that PVA fiber is the highest in terms of the aspect ratio compared to other fibers and the mixing rate is also highest, which lowers the fluidity of Hwangtoh mortar. From the analysis, it was found that the use of hydrophilic fibers such as Lyocell and polyamide was effective in preventing the deterioration to fluidity of Hwangtoh mortar that can result from fiber addition.

\subsection{Compressive strength}

The mechanical characteristics of fiber reinforced concrete are greatly affected by the amount of fiber added and by the aspect ratio[12,13]. Beaudoin[12] proved that the amount of fiber added and the aspect ratio can be generalized using fiber spacing.

$$
F_{s}=\frac{V_{f} d_{f}}{L_{f}}
$$

Figure 1 illustrates the relationship between fiber spacing and the relative ratio of compressive strength at 28 days. The compressive strength of each specimen was divided by the compressive strength of $\mathrm{N}$ specimen to calculate the relative ratio of compressive strength. The relative ratio of compressive strength of fiber-reinforced Hwangtoh mortar was measured to be $0.86-0.95$ regardless of fiber type, which is a slight decrease. This seems to be because the volume of pores and the number of fine pores had increased[12]. However, the fiber spacing had little effect on the relative ratio of compressive strength, regardless of fiber type. 


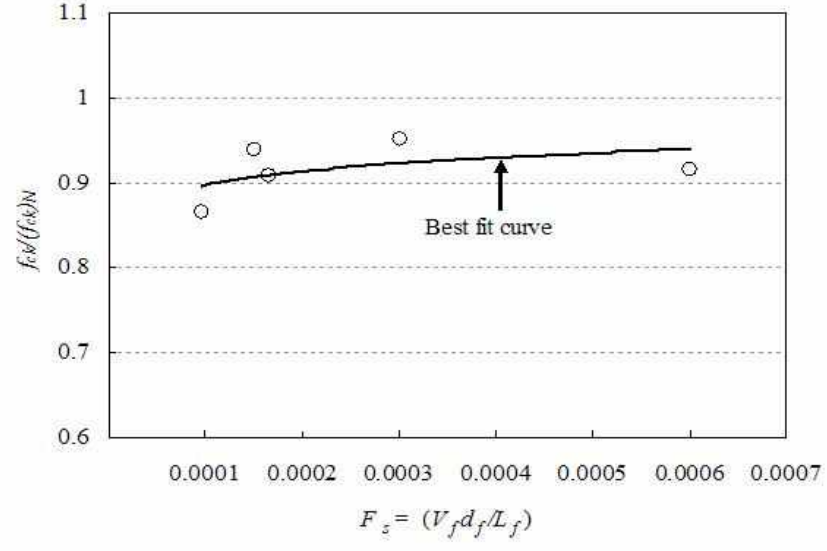

Figure 1. $f_{c k} /\left(f_{c k}\right)_{N}$ against fiber spacing

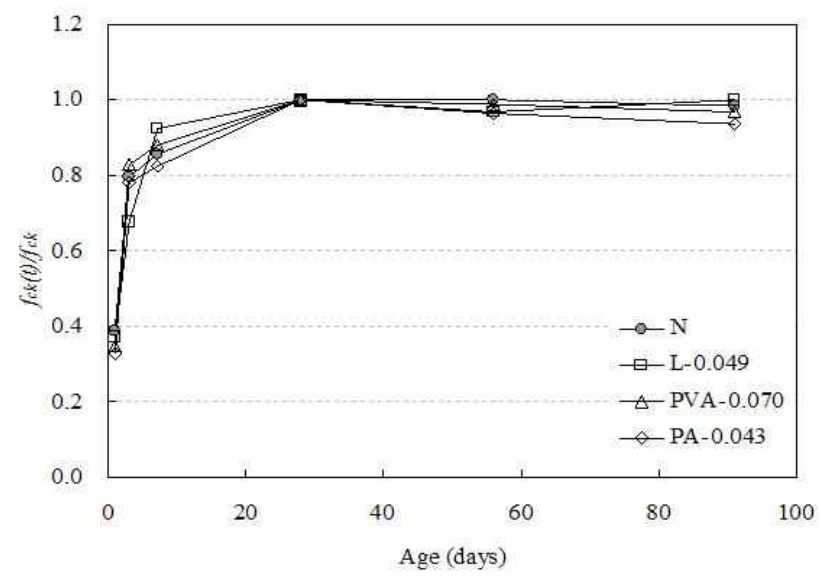

Figure 2. Typical compressive strength development against age

Figure 2 shows the typical development of compressive strength with age. Each age was converted to dimensionless time based on 28 days. The amount of lyocell added had little effect on compressive strength development. The development ratio of compressive strength was measured to be $0.66^{-} 0.83$ at 3 days, while it was 0.82-0.92 at 7 days, from which it can be interpreted that the strength development was great at an initial age. On the other hand, the strength development was rather low after 28 days.

The development ratio of compressive strength of Hwangtoh mortar was compared to the model equation for the compressive strength development of $\mathrm{N}$ specimen in ACI 209. The model equation for compressive strength development with age in ACI 209 is shown below.

$$
f_{c k}(t)=\frac{t}{A_{1}+B_{1} t} f_{c k}
$$

Here, $(t)$ is days. $\left(A_{1}\right)$ and $\left(B_{1}\right)$ are the constants for the development ratio of compressive strength at initial and later age, presented as 4.0 and 0.85 , respectively, for Ordinary Portland cement. The strength development ratio of the fiber-reinforced Hwangtoh mortar was set at constants $\left(A_{1}\right)$ and $\left(B_{1}\right)$ through a nonlinear regression analysis. As shown in Table $3,\left(A_{1}\right)$ and $\left(B_{1}\right)$ of the fiber-reinforced Hwangtoh mortar were shown to be between 1.25 and 1.49, and between 0.96 and 1.01, respectively, which means the fiber type and amount added had almost no effect on the strength development ratio. In addition, $\left(A_{1}\right)$ was lower than the constant value of $\mathrm{OPC}$ presented in ACI 209, but $\left(B_{1}\right)$ was higher than that. This may mean that the development ratio of the compressive strength of the fiber-reinforced Hwangtoh mortar was higher at initial age compared to that of $\mathrm{OPC}$, but slightly lower at later age. However, the fiber spacing had little effect on $\left(A_{1}\right)$ and $\left(B_{1}\right)$, as shown in Figure 3.

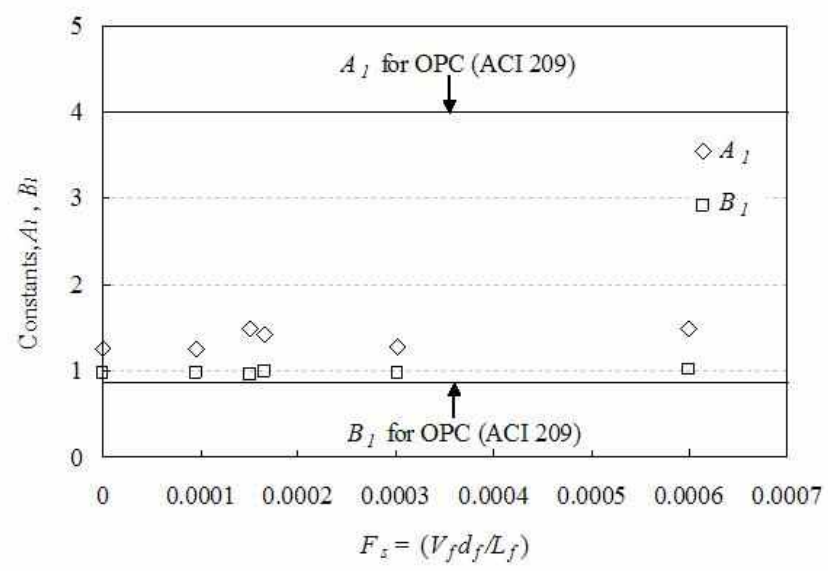

Figure 3. Determination of constants $A_{1}$ and $B_{1}$ in Eq. (2) 
Table 3. Test results summary

\begin{tabular}{|c|c|c|c|c|c|c|c|c|c|c|c|c|c|c|c|c|c|c|c|}
\hline \multirow[t]{2}{*}{ Specimen } & \multirow{2}{*}{$\begin{array}{l}\text { Flow } \\
(\mathrm{mm})\end{array}$} & \multicolumn{6}{|c|}{$\begin{array}{c}\text { Compressive strength, } \\
\qquad f_{c k}(\mathrm{MPa})\end{array}$} & \multicolumn{3}{|c|}{$\begin{array}{c}\text { Constants from } \\
\text { nonlinear regression } \\
\text { analysis }\end{array}$} & \multicolumn{2}{|c|}{$\begin{array}{l}\text { Modulus of } \\
\text { elasticity }\end{array}$} & \multicolumn{2}{|c|}{$\begin{array}{l}\text { Modulus of } \\
\text { rupture }\end{array}$} & \multicolumn{2}{|c|}{$\begin{array}{l}\text { Splitting } \\
\text { tensile } \\
\text { strength }\end{array}$} & \multicolumn{3}{|c|}{ Toughness index } \\
\hline & & 1day & 3days & 7days & 28days & 56 days & 91days & $A_{1}$ & $B_{1}$ & $r^{2}$ & $\begin{array}{c}E_{c} \\
(\mathrm{MPa})\end{array}$ & $\frac{E_{c}}{\sqrt{f_{c k}}}$ & $\begin{array}{c}f_{r} \\
(\mathrm{MPa})\end{array}$ & $\frac{f_{r}}{\sqrt{f_{c k}}}$ & $\begin{array}{c}f_{s p} \\
(\mathrm{MPa})\end{array}$ & $\frac{f_{s p}}{\sqrt{f_{c k}}}$ & $I_{5}$ & $I_{10}$ & $I_{20}$ \\
\hline$N$ & 213 & 10 & 20.6 & 22.2 & 25.9 & 25.9 & 25.5 & 1.26 & 0.97 & 0.96 & 15655 & 3150 & 1.76 & 0.345 & 1.53 & 0.301 & 2.63 & 2.88 & - \\
\hline$L-0.049$ & 195 & 9 & 16.5 & 22.4 & 24.3 & 23.5 & 24.3 & 1.49 & 0.96 & 0.97 & 14577 & 2987 & 2.54 & 0.516 & 2.30 & 0.467 & 2.73 & 3.06 & - \\
\hline$L-0.098$ & 202 & 9.9 & 19.1 & 20.8 & 24.6 & 24.7 & 24.5 & 1.28 & 0.97 & 0.98 & 15228 & 3043 & 2.47 & 0.499 & 2.16 & 0.436 & 2.62 & 2.91 & - \\
\hline L-0.195 & 185 & 8.2 & 16.6 & 19.7 & 23.7 & 22.2 & 21.7 & 1.50 & 1.01 & 0.96 & 13962 & 2875 & 2.27 & 0.466 & 2.15 & 0.442 & 3.09 & 4.15 & 4.83 \\
\hline PVA-0.07 & 208 & 7.8 & 18.6 & 19.7 & 22.4 & 22.2 & 21.6 & 1.25 & 0.97 & 0.92 & 14277 & 2987 & 1.96 & 0.415 & 1.71 & 0.362 & 3.72 & 4.97 & 5.89 \\
\hline PA-0.043 & 220 & 7.7 & 18.3 & 19.4 & 23.5 & 22.6 & 22.0 & 1.42 & 0.99 & 0.93 & 16343 & 3351 & 2.40 & 0.494 & 1.95 & 0.401 & 2.7 & 3.19 & - \\
\hline
\end{tabular}

\subsection{Stress-strain curve}

The stress ${ }^{-}$strain curve of the fiber reinforced Hwangtoh mortar is illustrated in Figure 4. The stress-strain curve of Hwangtoh mortar was similar to that of $\mathrm{N}$ specimen in terms of initial stiffness and strain at maximum stress, regardless of fiber type and the amount of lyocell added. A more gradual decline in the curved line of the fiber-reinforced Hwangtoh mortar was found compared to that of $\mathrm{N}$ specimen after the maximum stress. In particular, the lyocell-added specimen showed a more gradual decline. There was almost no effect on the slope from the amount of fiber added after the maximum stress, from which it is believed that the stress-strain was barely affected since a small amount of fiber, $0.195 \%$ or less, was added.

\subsection{Modulus of elasticity}

Table 3 shows the modulus of elasticity $\left(E_{c}\right)$ normalized by the square root of compressive strength $\left(\sqrt{f_{c k}}\right)$ of Hwangtoh mortar. As more lyocell was added, a slight decrease in the normalized modulus of elasticity $\left(E_{c} / \sqrt{f_{c k}}\right)$ was found in Hwangtoh mortar and its of specimen with $0.195 \%$ lyocell showed an $11 \%$ downfall compared to $\mathrm{N}$ specimen. $E_{c} / \sqrt{f_{c k}}$ of Hwangtoh mortar reinforced by the optimal amount of fiber was measured to be $4 \%$ lower than that of $\mathrm{N}$ specimen. On the other hand, for the fiber-reinforced Hwangto mortar shown in Figure 5, the wider the fiber spacing, the lower $E_{c} / \sqrt{f_{c k}}$. The downfall was within about 9\% when the fiber spacing was 0.0003 or narrower, which is small enough to ignore

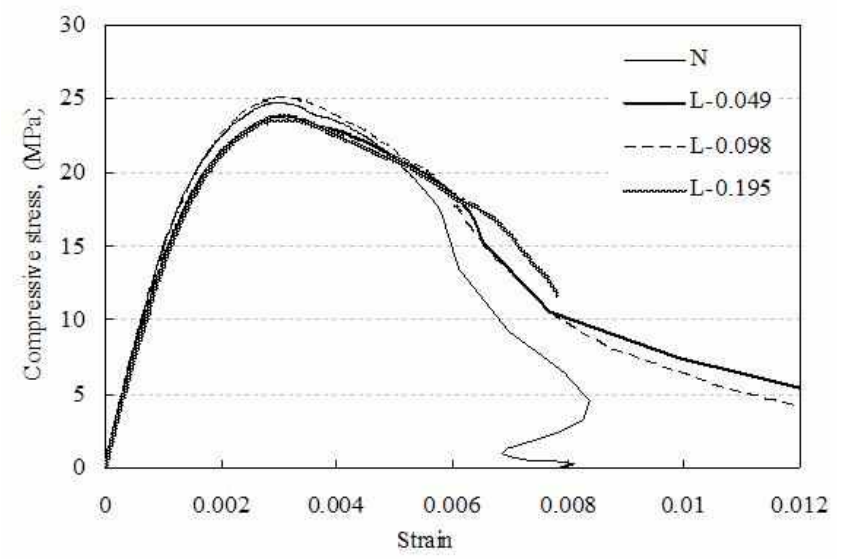

Figure 4. Typical stress-strain relationship

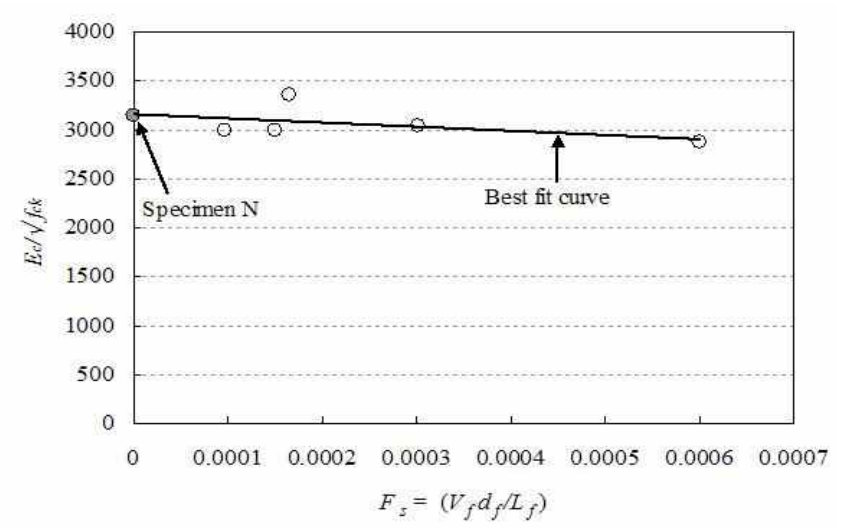

Figure 5. $E_{c} / \sqrt{f_{c k}}$ against fiber spacing 


\subsection{Splitting tensile strength}

As shown in Table 3, the splitting tensile strength $\left(f_{s p}\right)$ normalized by the square root of compressive strength $\left(\sqrt{f_{c k}}\right)$ was increased by fiber type and amount of lyocell added. The specimen with an optimal amount of lyocell was measured to be 0.467 , which was highest but later showed a gradual decrease. In addition, normalized splitting tensile strength of specimen reinforced with lyocell and polyamide were measured to be 1.55 and 1.33 times higher, respectively, than that of $\mathrm{N}$ specimen.

Figure 6 illustrates the relationship between fiber spacing and $f_{s p} / \sqrt{f_{c k}}$ of hydrophilic fiber-reinforced Hwangtoh mortar. The more space there is between fibers, the higher $f_{s p} / \sqrt{f_{c k}}$ of the fiber-reinforced Hwangtoh mortar. The rate of increase was constant at 0.436 when the fiber spacing was 0.00015 or wider. Based on the experiment results, $f_{s p} / \sqrt{f_{c k}}$ of the fiber-reinforced Hwangtoh mortar can be expressed as a function for the fiber spacing.

$$
\frac{f_{s p}}{\sqrt{f_{c k}}}=0.36 \exp \left(489 F_{s}\right)
$$

\subsection{Modulus of rupture}

The modulus of rupture $\left(f_{r}\right)$ normalized by the square root of compressive strength $\left(\sqrt{f_{c k}}\right)$ of Hwangto mortar, $f_{r} / \sqrt{f_{c k}}$, as was also shown in Table 3, improved by fiber type and the amount of lyocell added. $f_{r} / \sqrt{f_{c k}}$ was the highest in the specimen reinforced by the optimal amount of lyocell, but subsequently decreased. In addition, $f_{r} / \sqrt{f_{c k}}$ of lyocell- and polyamide-reinforced Hwangtoh mortar was 1.4 times higher compared to the $\mathrm{N}$ specimen,

In addition, as shown in Figure 7, with wider fiber spacing, there was a slightly higher increase in $f_{r} / \sqrt{f_{c k}}$ of the fiber-reinforced Hwangtoh mortar. The increase ratio was constant at 0.49 when the fiber spacing was 0.00015 or wider. As for $f_{r} / \sqrt{f_{c k}}, \quad f_{r} / \sqrt{f_{c k}}$ of the hydraulic fiber-reinforced Hwangtoh mortar can be expressed as a function for the fiber spacing.

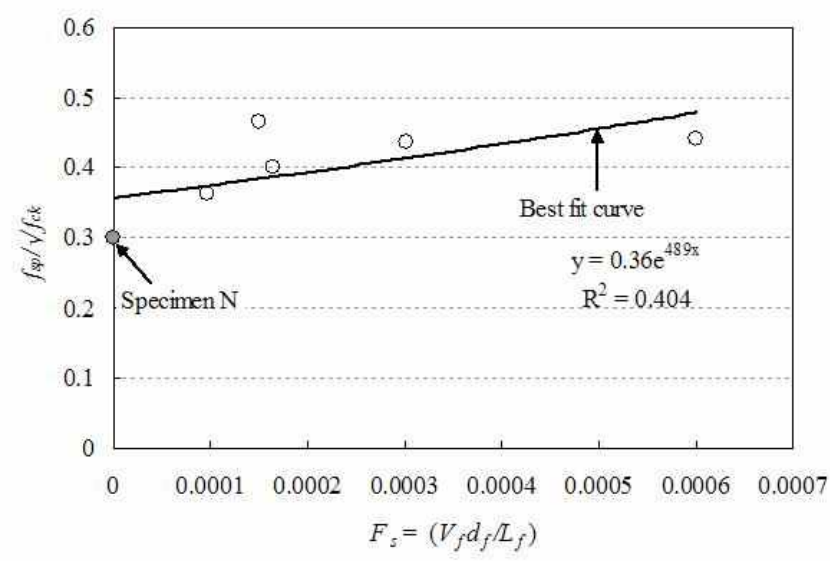

Figure 6. $f_{s p} / \sqrt{f_{c k}}$ against fiber spacing

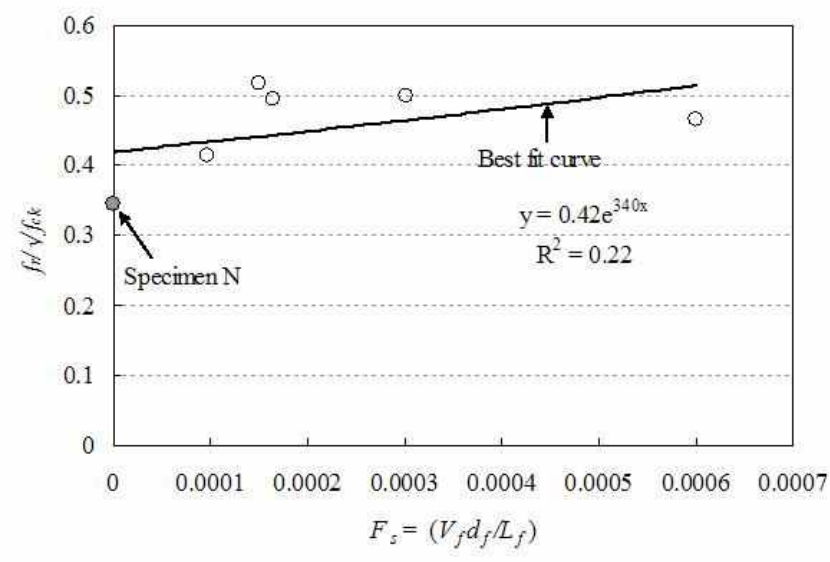

Figure 7. $f_{r} / \sqrt{f_{c k}}$ against fiber spacing

$$
\frac{f_{s p}}{\sqrt{f_{c k}}}=0.42 \exp \left(340 F_{s}\right)
$$

\subsection{Toughness index}

The flexural ductility in the load-deflection curve was assessed by calculating the toughness index as shown in Figure 8 according to ASTM C-1018[12]. Table 3 shows the toughness index of Hwangtoh 
mortar reinforced by fiber type and the amount of lyocell added. $I_{5}$ and $I_{10}$ of $\mathrm{N}$ specimen with no fiber were measured to be 2.63 and 2.88 , respectively, and $R_{5}\left(=I_{10}-I_{5}\right)$ was measured to be 0.24 . The toughness index of the fiber reinforced Hwangtoh mortar was shown to be constant up to $0.098 \%$ lyocell, but greatly increased at $0.195 \%$. $I_{5}$ and $I_{10}$ of the Hwangtoh mortar reinforced by 0.195\% lyocell were 1.18 and 1.44 times higher, respectively, than in $\mathrm{N}$ specimen, and even $I_{20}$ $\left(10.5 \delta_{c}\right)$ can be measured. In addition, $R_{5}$ of $0.195 \%$ lyocell-reinforced Hwangtoh mortar was greatly increased to be 4.33 times higher than that of $\mathrm{N}$ specimen. However, the toughness index of the PVA-reinforced Hwangtoh mortar was higher than that of other reinforced specimens. $I_{5}$ and $I_{10}$ of the toughness index of the PVA-reinforced Hwangtoh mortar were 1.41 and 1.72 times higher, respectively, than those of $\mathrm{N}$ specimen.

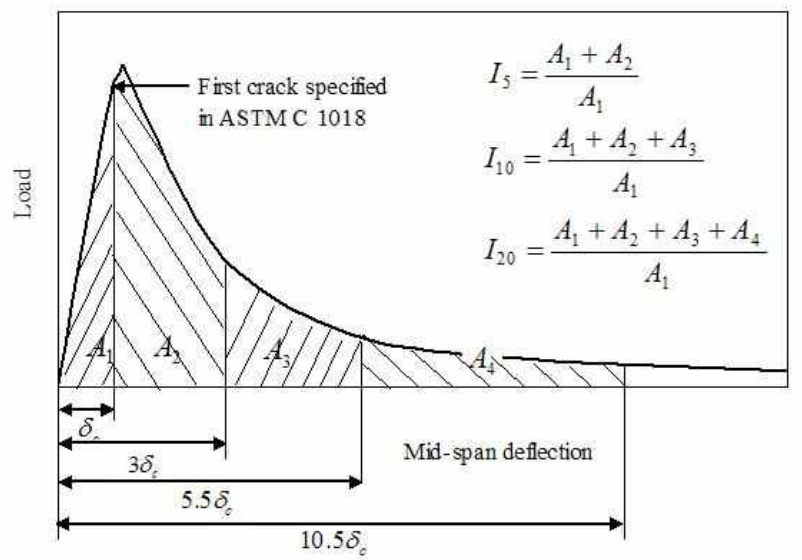

Figure 8. Calculation procedure for toughness index

Figure 9 shows the toughness index of Hwangtoh mortar depending on the fiber spacing. The index of the lyocell and polyamide-reinforced specimens was constant up to a fiber spacing of 0.0003 , but greatly increased after this point. However, the toughness index of the PVA-reinforced specimens was high, even at close fiber spacing. This is because the area of elastic range up to $\delta_{c}$ for the fiber-reinforced specimen was relatively smaller than the area of inelastic range between $3 \delta_{c}$ and $5.5 \delta_{c}$. As such, to improve the toughness index of Hwangtoh mortar, fiber with the spacing of 0.0003 or wider should be added, and fiber that can increase the area of elastic and inelastic range needs to be used, as well.

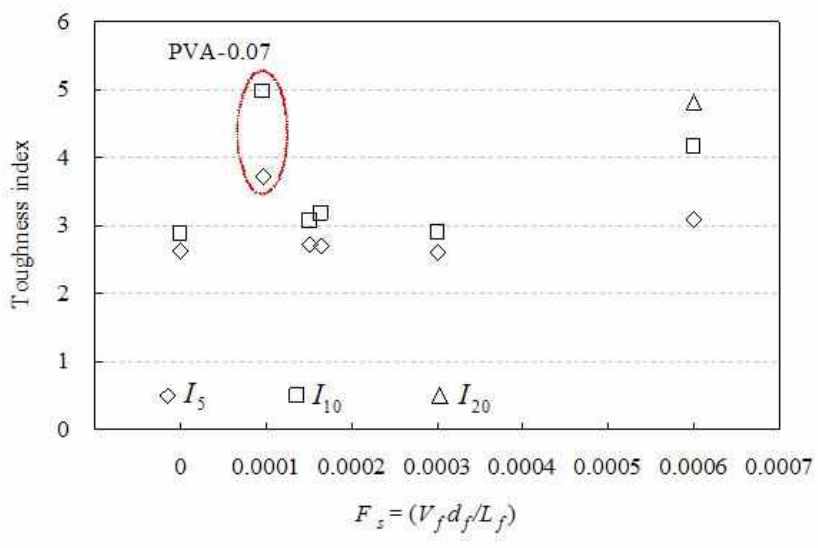

Figure 9. Toughness index against fiber spacing

\section{Conclusion}

The applicability of hydrophilic fiber to improve the tensile performance of Hwangtoh mortar was verified, and through the experiment and by considering the above, the following conclusion can be drawn.

1) When hydrophilic fiber such as lyocell and polyamide was added in an optimal amount, the fluidity of Hwangtoh mortar was somewhat deteriorated.

2) The compressive strength of Hwangtoh mortar was 1.7 times higher at 3 days compared to the ACI 209 model regardless of fiber type or the amount of lyocell added. However, the strength development was shown to be 0.87 times at 91 days, which is significantly lower.

3) The splitting tensile strength and modulus of 
rupture normalized by the square root of the compressive strength of fiber-reinforced Hwangtoh mortar was increased as the fiber spacing was wider. But the rate of increase was constant at fiber spacing of 0.00015 or wider.

4) The toughness index of Hwangtoh mortar was highest in the specimen with $0.07 \%$ PVA or $0.195 \%$ lyocell added, reaching about 4.56 . In particular, to increase the area of elastic and inelastic behavior in the load-deflection relationship while improving the toughness index, fiber with spacing of 0.0003 or wider was required.

\section{Acknowledgement}

This work was supported by National Research Institute of Cultural Heritage and a grant(10High tech Urban B01) from High-tech Urban Development Program funded by the Ministry of Land, Transport and Maritime Affairs.

\section{References}

1. Korea Concrete Institute. [Concrete and Environment], Seoul (Korea): Korea Concrete Institute; 2010. 299 p. Korean.

2. Lee SS, Won C, Kim DS, Park SJ. A Study on the Engineering Properties of Concrete Using Blast-furnace Slag Powder. Journal of the Korea Concrete Institute 2000;12(4):49-58.

3. Jo BW, Park MS, Park SK. Strength Development and Hardening Mechanism of Alkali Activated Fly Ash Mortar. Journal of the Korea Concrete Institute 2006;28(4):449-58.

4. Choi HY, Hwang HZ, Kim MH, Kim MH. A Study on the Development of Hwangtoh Admixture for the Application of Cement Mortar. Journal of the Architectural Institute of Korea 2000;16(6):95-102

5. Yang KH, Hwang HJ, Kim SY, Song JK. Development of a Cementless Mortar using Hwangtoh Binder. Building and Environments 2007;42(10):3717-25.

6. Yang KH, Hwang HJ, Lee S. Effects of Water-Binder Ratio and Fine Aggregate-Total Aggregate Ratio on the Properties of
Hwangtoh-Based Alkali-Activated Concrete. Journal of Materials in Civil Engineering ASCE 2010;22(9):887-96.

7. Yang KH, Kim SY, Song JK. The Mechanical Characteristics of Concrete Mixed with Activated Hwangtoh and Specialty Cellulose Fiber. Journal of the Architectural Institute of Korea 2006;22(1):111-8.

8. ACI Committee 209. ACI 209R-92: Prediction of Creep, Shrinkage and Temperature Effects in Concrete Structures. 1st ed. Farmington Hills (MI): American Concrete Institute; 1992 $47 \mathrm{p}$.

9. ASTM International. ASTM C 1018 - 97 Standard Test Method for Flexural Toughness and First-Crack Strength of Fiber-Reinforced Concrete (Using Beam With Third-Point Loading). 1st ed. West Conshohocken: ASTM; 1997. 8 p.

10. Korea Industrial Standard. [Testing Method for Compressive Strength of Hydraulic Cement Mortars (KS L 5105)]. Seoul (Korea): Korea Industrial Standard; 2007. p. 1-9. Korean,

11. ACI Committee 318. Building Code Requirements for Structural Concrete (ACI 318-11) and Commentary (ACI 318R-11). Farmington Hills(M): American Concrete Institute; 2011. $503 \mathrm{p}$

12. Beaudoin JJ. Handbook of Fiber Reinforced Concrete: Principles, Properties, Developments and Applications. USA Park Ridgw, N.J. 1990. 332 p.

13. Hannant DJ. Fibre Cements and Fibre Concrete. Lincoln (UK): John Wiley \& Sons UK; 1978. 219 p.

14. Yang $\mathrm{KH}$. Tests on Concrete Reinforced with Hybrid or Monolithic Steel and PVA Fibers. ACI Materials Journal, 2011;29(1):504-11 